\title{
Incerteza e esforço inovativo no pensamento keynesiano e neo-schumpeteriano
}

\author{
Uncertainty and the innovative behavior on Keynesian and Neo-schumpeterian \\ approaches
}

Thiago Cavalcante*

\begin{abstract}
Resumo
Este artigo analisa como elementos da teoria keynesiana e evolucionária - incerteza, investimento e a formação de expectativas - demonstram-se relevantes no processo decisório orientado à mudança teológica das firmas. Emprega-se o método epistemológico para articular a noção de temporalidade das expectativas e decisões de investimentos em inovação presente nas duas abordagens teóricas. Dentre os resultados, destaca-se que a emergência de um novo paradigma tecnológico altera a eficiência marginal do capital previamente mobilizado, visto que as inovações radicais alteram às quase-renda vinculadas aos rendimentos prospectivos dos bens de capital. Logo, as decisões de investimentos relativas a inovações radicais (longo prazo) demonstram-se mais suscetíveis à incerteza do que as decisões de investimentos em inovações incrementais (curto prazo), dado o processo de aprendizado.
\end{abstract}

Palavras-chave: Teoria keynesiana; Teoria evolucionária; Expectativas; Incerteza; Inovação.

Classificação JEL: B2, B5, B22, B52, E12.

\begin{abstract}
This article analyzes how elements of Keynesian and evolutionary theory - uncertainty, investment and the formation of expectations - prove to be relevant in the decision-making process aimed at theological change of firms. The epistemological method is used to articulate the notion of temporality of expectations and investment decisions in innovation present in both theoretical approaches. Among the results, it is highlighted that the emergence of a new technological paradigm alters the marginal efficiency of previously mobilized capital, as radical innovations alter the quasi-rent linked to prospective adjustments of capital goods. Therefore, investment decisions related to (long term) radical innovations are more susceptible to uncertainty than investment decisions related to (short term) incremental innovations, given the learning process.
\end{abstract}

Keywords: Keynesian theory; Evolutionary theory; Expectations; Uncertainty; Innovation.

JEL Classification: B2, B5, B22, B52, E12.

\footnotetext{
"Professor Adjunto da Faculdade de Administração, Contabilidade e Economia (FACE), Universidade Federal de Goiás (UFG). Contato: thiagocavalcante@ufg.br
} 


\section{Introdução}

Na Teoria Geral do Emprego, do Juro e da Moeda (TG), Keynes (1936, [1996]) preocupa-se com o funcionamento de uma economia monetária e explicita a tese de que a moeda não consiste em um elemento neutro e, consequentemente, a variação em seus respectivos estoques afeta o comportamento real do sistema econômico. Por isso, advoga que os gastos com tecnologia, isto é, com bens de capital, são motivados pela expectativa de obtenção de rendimentos durante a vida útil do bem, desde que as expectativas desses rendimentos sejam superiores (ou iguais) ao retorno esperado para os rendimentos monetários providos pelo sistema financeiro, conforme taxa de juros vigente. Em suma, a TG permite considerar que a inovação associada à ampliação da margem de rendimentos sobre o custo adicional de produção de um bem de capital determina, em conjunto com a taxa de juros, o nível de investimento e, logo, o nível de produção agregada.

Por sua vez, a teoria do desenvolvimento econômico de Schumpeter (1911 [1997]) trata a inovação como um fator endógeno ao sistema econômico, autônomo e fundamental para a dinâmica capitalista. Partindo dessa premissa, os economistas neo-schumpeterianos de tradição neo-schumpeteriana, em rejeição à hipótese de maximização neoclássica, argumentaram que as decisões sobre o nível de investimento são fomentadas pelas estratégias inovadoras que os agentes assumem no mercado, dados os desequilíbrios presentes na economia. Essa concepção sustenta o argumento central da abordagem evolucionária de que os processos de mudança de longo prazo e progressivos constituem-se nos elementos determinantes das decisões econômicas, que quando conhecidos e articulados geram os impulsos responsáveis pelo desenvolvimento da atividade econômica.

Nesse contexto, uma articulação entre as abordagens keynesiana e (neo)schumpeteriana pode ser proposta, uma vez que a trajetória tecnológica problematizada pela corrente (neo)schumpeteriana pode afetar um elemento vital na teoria keynesiana - o investimento. Diante desses aspectos, questiona-se: como a incerteza e as expectativas afetam o esforço inovativo das firmas no pensamento keynesiano e neo-schumpeteriano? Para lidar com essa questão, este artigo objetiva analisar a relação epistemológica entre a semântica keynesiana e neo-schumpeteriana 
de incerteza, expectativa e esforço inovativo. Especificamente, busca-se comparar a noção de esforço inovativo sob condição de incerteza a partir da epistemologia vinculada ao binômios probabilidade-peso do argumento, expectativa-estado de confiança e busca-rotina-seleção.

Para a consecução desse objetivo, realiza-se, primeiramente, uma análise de caráter filosófico-metodológico da noção de conhecimento vinculado à incerteza e à expectativa. Na sequência, elabora-se uma análise similar para a noção de incerteza e expectativa do esforço inovativo tratada por autores neo-schumpeterianos, para, finalmente, demarcar os aspectos antológicos convergentes entre essas duas vertentes do pensamento econômico.

A epistemologia conjuga o núcleo comum das teorias (Colin-Jaeger e Delcey, 2020), isto é, o objeto semântico e ontológico teorizado nos distintos campos teóricos investigados, o que implica na compreensão sincrônica do significado preconizado pelo(s) autor(es) previamente selecionados. Assim, o emprego do método epistemológico permite interpretar o sentido de um significado contido em um modelo teórico-conceitual a partir dos princípios e leis gerais de uma outra estrutura ou corrente científica. Nesse sentido, a analise proposta se dará em dois planos: a) semântico, que trata do significado de incerteza em Keynes e em autores neo-schumpeterianos; e, b) ontológico, alusivo à relação desses significados com à propensão e à direção do esforço inovativo. Essa abordagem tem sido empregada estudos que buscam articular a teoria econômica a outros ramos teóricos (Dow, 1995; Dunn, 2018; Heesen e van der Kolk, 2016; Helzner, 2013; Jones, 2011; Kelly, 2003).

A contribuição deste artigo reside na associação entre a abordagem keynesiana e neo-schumpeteriana para explicar como a noção de conhecimento presente nessas correntes vincula-se ao processo de formação de expectativas relacionadas ao esforço inovativo empresarial, sob distintas incertezas. Para isso, o texto está estruturado em cinco seções, incluindo essa introdução. A seção 2, discute incerteza, investimento e a formação de expectativas em Keynes. A seção 3 expõe a abordagem neo-schumpeteriana, com a finalidade de desenvolver o papel da 
inovação no sistema econômico. A seção 4 debate a articulação entre as duas abordagens. Por fim, a seção 5 esboça as considerações finais.

\section{Incerteza, formação de expectativas e investimento em Keynes}

Esta seção realiza uma análise epistemológica dos conceitos de incerteza, expectativa e investimento presentes na obra de Keynes (1921 e 1936 [1996]), com o intuito de se estabelecer uma síntese sincrônica da noção de conhecimento intrínseca aos binômio probabilidade-peso do argumento expresso no Tratado sobre Probabilidade (TP) e expectativa-estado de confiança apresentado na TG.

A incerteza representa um elemento fundamental na abordagem keynesiana. A principal contribuição de Keynes a esse respeito foi desenvolvida em seu TP em que Keynes (1921) atribui a incerteza ao fato das ocorrências de flutuações de investimento e preferência pela liquidez. Seu argumento postula que, por natureza, os indivíduos apresentam um grau de desconfiança em relação ao futuro, motivo pelo qual buscam preservar o estoque de moeda disponível, como uma forma de segurança em relação à incerteza que permeia suas respectivas decisões de consumo e investimento.

Nesse sentido, uma decisão coerente exige dos indivíduos um raciocínio pautado em elementos previamente conhecidos, capazes de articular suas expectativas com a probabilidade de sucesso de suas escolhas, por meio de comparações lógicas. Para tanto, rejeitou o pressuposto clássico de incerteza atrelada ao risco, baseada em uma distribuição de probabilidade bem definida, na qual os agentes econômicos alcançariam decisões ótimas. Consequentemente, desenvolveu uma teoria de probabilidade mais ampla e uma análise menos simplificada sobre as consequências da incerteza sobre o sistema econômico.

No TP, Keynes (1921) trata a probabilidade como o grau de crença racional que os indivíduos atribuem aos diversos cursos de decisão. Para que uma decisão seja considerada racional precisa ser o "resultado de um processo de raciocínio fundamentado no conhecimento" (Terra e Goudard, 2015, p. 4). Isso porque a probabilidade representa as relações lógicas estabelecidas entre um conjunto de 
proposições (hipóteses formuladas) e as conclusões elaboradas pelos indivíduos. Desse modo, se o conhecimento de uma proposição justificar um grau de crença racional de uma determinada conclusão, é possível afirmar que existe uma relação de probabilidade entre a proposição e a conclusão. Logo, a probabilidade é definida em decorrência das evidências, ou seja, do conhecimento indutivo.

conhecimento humano é frequentemente alcançado indutivamente e, por isso, compartilha a incerteza característica de qualquer indução. Porquanto, o raciocínio indutivo se utiliza de indícios, ou seja, comportamentos prováveis, passíveis de reprodução constante, capaz de subsidiar a crença de reprodução sistêmica. Em outras palavras, qualquer decisão humana é baseada em uma incerteza fundamental e, logo, baseia-se em algum tipo de conhecimento exploratório. Para Keynes (1921, p. 288, tradução própria) "a indução pura pode ser utilmente empregada para fortalecer um argumento se, após um certo número de instâncias, os indícios forem examinados", determinando uma probabilidade finita a favor da generalização, isto é, a crença racional. $\bigcirc$ impacto do conhecimento sobre a crença racional dar-se-á por meio do peso do argumento.

Amparando-se em Vercelli (2010), vê-se que o TP não apresenta um conceito uniformizado para o peso do argumento, que está relacionado ao grau de conhecimento relevante para a probabilidade decisória em três perspectiva: a) quantidade de evidências relevantes para elaborar conclusões a partir do conjunto de proposições disponíveis; b) uma espécie de equilíbrio entre os montantes absolutos de conhecimento e ignorância relevantes à crença no argumento; e, c) grau de completude das evidências em que a probabilidade se fundamenta.

Pode-se afirmar que a noção de peso do argumento imputa ao conhecimento a responsabilidade de estabelecer parâmetros para as decisões individuais. Portanto, quanto maior e melhor for o conhecimento acerca das evidências (peso do argumento), menos incertas serão as conclusões que os agentes obterão a partir das proposições preliminares. Nesse caso, conforme salienta o próprio Keynes (1921), a probabilidade pode ser reforçada e tende a aumentar em direção à certeza sempre que a multiplicação dos indícios verificados a cada instância viabiliza inferências capazes de fortalecer o peso do argumento. 
É importante destacar, conforme apontam Vercelli(2010), Terra e Goudard (2015), que a noção de peso do argumento desenvolvida por Keynes é objeto de controvérsias na literatura econômica. Ainda assim, a noção levantada no TP demonstra-se relevante para capturar o papel do conhecimento na estimativa da crença das probabilidades examinadas pelos indivíduos no curso do processo decisório (Crocco, 2003). Nesse particular, o conhecimento pode ser classificado em conhecimento direto e indireto. Por conhecimento direto entende-se a percepção decorrente das "experiências dos indivíduos que, por sua vez, envolvem (i) o uso dos sentidos, (ii) a compreensão de significados e (iii) a percepção de dados derivados dos fatos" (Ferrari Filho; Terra, 2016, p. 79). Trata-se do conhecimento gerado por meio da mera observação, resultando em premissas que nem sempre se demonstram coesas à realidade. Em razão dessa condição, conforme Keynes (1921), ainda que o conhecimento direto resulte em premissas verdadeiras, sempre será limitado, pois raramente será capaz de apresentar conjecturas completas acerca das informações capturadas nas observações realizadas pelos indivíduos.

Do conhecimento direto transita-se para uma espécie de conhecimento propositivo. Assim, por meio de "um processo mental somos capazes de passar do conhecimento direto das coisas a um conhecimento de proposições sobre as coisas das quais temos sensações ou entendemos o significado (Keynes, 1921, p. 25, tradução própria). Nesse particular, atrela-se o conhecimento direto à práxis não heurísticas de suporte às decisões individuais.

O conhecimento indireto, por sua vez, consiste na percepção decorrente de condicionamentos lógicos realizados pelos indivíduos a partir das premissas intuídas pelo conhecimento direto. Doutro modo, corresponde a conclusões lógicas, às quais apresentam elevado grau de crença e que são obtidas pelos indivíduos por meio das experiências que formam seu conhecimento direto. Nesse caso, o conhecimento indireto desenvolve a partir dos argumentos, isto é, por meio da percepção da relação de probabilidade da proposição, que se busca relacionar ao conhecimento de outras proposições (Keynes, 1921). A análise semântica permite diferenciar o conhecimento direto e indireto entre a crença racional baseada na aprendizagem e a crença sustentada em argumentos, ou seja, práxis heurísticas. 
No TP, a incerteza e o processo decisório são tratados sob o prisma do binômio probabilidade-peso do argumento, enquanto na TG é acentuado o binômio expectativas-estado de confiança. Para Keynes (1936 [1996]), em uma economia monetária de base produtiva, as expectativas e decisões relativas ao nível de produção e de investimento assumem um papel essencial na determinação do emprego e da renda real. Isto posto, define-se que o nível de equilíbrio da demanda agregada depende, em última instância, dos componentes da demanda que são determinados autonomamente.

Portanto, se a propensão ao consumo das famílias e os investimentos das firmas resultarem em uma demanda monetária insuficiente para absorver a produção agregada, o nível real do emprego se reduzirá até ficar abaixo da oferta de mão-deobra potencialmente disponível ao salário real em vigor, de modo que o salário real de equilíbrio será superior à desutilidade marginal do nível de emprego de equilíbrio. Logo, em um ambiente de incertezas fundamentais, o lucro futuro dos empresários e, portanto, a base para os investimentos correntes, não poderão ser previstos de forma confiável a partir das informações de mercado existentes, tão pouco serem determinados endogenamente em função da poupança planejada. Ao contrário, as expectativas de investimento dependerão das expectativas exógenas, que Keynes atribuiu ao animal spirits, seja no curto prazo ou no longo prazo, quando as expectativas dos empresários forem ajustadas.

Esse argumento reconhece a incerteza como um elemento proeminente para a demanda agregada e o nível de emprego e, portanto, para o crescimento econômico:

Em crescimento, com expectativas otimistas de lucro futuro, os investimentos geram mais empregos, maior nível de produto e de renda e, portanto, maior nível de consumo e poupança. Em depressão, perspectivas pessimistas de lucro geram frustração de lucro da indústria de bens de capital, queda de emprego e de renda e, portanto, queda nos níveis de consumo e poupança (Silva, 1996, p. 11).

Nas flutuações do nível de investimento, movido pelas expectativas dos empresários reside a chave para a compreensão dos movimentos cíclicos do capitalismo. De acordo com Keynes (193. [1996], p. 71), "uma simples mudança de expectativa é capaz, no decorrer do período em que a mesma se verifica, de provocar 
uma oscilação comparável à de um movimento cíclico". Nesse sentido, em termos de política econômica, os postulados de sugere a criação de margens para à flexibilidade de preços, através da desregulação, disseminação de informação de mercado e remoção de falhas de coordenação empresarial, além da promoção da concorrência global com taxas de câmbio spot perfeitamente flexíveis, de forma que seja possível realizar ajustes empresariais, quase que simultâneos.

Com isso, Keynes coloca o investimento empresarial como um elemento essencial para a dinâmica capitalista, notadamente materializada na forma de uma firma -núcleo operacional desse investimento, conforme destacam Aidar e Terra (2019). Na TG, a definição de investimento abrange o "aumento do equipamento de capital, quer ele consista em capital fixo, capital circulante ou capital líquido" (Keynes, 1936 [1996], p. 93). Em termos semânticos, vislumbra-se a definição keynesiana de investimento como sendo o esforço inovativo operado pelos empresários, no âmbito da firma, expresso pela aquisição de bens de capital com vista à expansão da capacidade produtiva e, portando, do lucro. Nesse particular, o empresário estima a taxa de retorno de seu investimento a partir da projeção do nível de lucro esperado, mensurado pelo conhecimento direto do comportamento das variáveis de mercado e do custo de expansão da capacidade produtiva, dada pela inovação viabilizada pela aquisição de novos equipamentos. Assim, as decisões de investimentos são definidas pela Eficiência Marginal do Capital, que permite ao empresário intuir o "estado de confiança" compatível com os rendimentos esperados.

Para Keynes (1936 [1996]), em qualquer decisão de investimento, o empresário se vê compelido a considerar três incertezas de caráter fundamental - de técnica, gerenciais e de mercado. Isso porque, qualquer investimento em inovação se esbarra em descontinuidades produtivas provocadas pelo custo de uso dos equipamentos adquiridos (incerteza de técnica). Da mesma maneira, a direção da inovação deverá exercer influência sobre à taxa de salário pela qual se espera remunerar o trabalhador envolvido com a nova tecnologia, o que gera incertezas gerenciais. Ademais, o valor futuro da série de rendimentos esperados para a nova tecnologia de produção dependerá da demanda de mercado, sujeita à renda corrente dos consumidores e à taxa de juros. 
De forma secundária, a inovação empreendida será influenciada pelo preço e disponibilidade de insumos, aspectos que, associados, caracterizam incertezas de mercado. Conjuntamente, essas incertezas gravitam em torno das expectativas do empresário no que se pode denominar de zona de incerteza da firma, resultando em incertezas tecnológicas.

Conforme a semântica vislumbrada na TG, as expectativas dos empresários podem ser sintetizadas como a esperança de rendimento fundamentada nas conclusões racionais obtidas pelos empresários, quando esses acionam o próprio conhecimento direto (percepção do negócio, prática gerencial, demanda e concorrência, por exemplo) para desenvolver argumentos (conhecimento indireto) que sustentem um estado de confiança.

Nesse particular, a confiança atribuída ao investimento projetado deverá contemplar variáveis que permitam estimar os rendimentos provenientes do bem de capital adquirido, como: receitas esperadas, os custos de produção, e, por fim, a taxa de juros da economia. Essas variáveis, segundo Terra (2015), balizarão as expectativas dos empresários, tornando o investimento desfavorável sempre que as expectativas de receitas forem baixas e os custos de produção forem altos e/ou crescentes, o que pode ocorrer concomitantemente. No caso de taxas de juro elevadas, o investimento produtivo demonstrar-se-á desfavorável em relação ao investimento financeiro, representando, assim, um desestimulo ao esforço inovativo empresarial. A partir da semântica de confiança, é possível intuir na TG duas espécies de conhecimento: conhecimento gerencial e conhecimento de mercado. Por conhecimento individual, entende-se o conhecimento gerencial como sendo o acúmulo de aprendizado tácito, que pode ser aperfeiçoado por técnicas de gestão, mas que advém, sobretudo, da própria experiência empreendedora.

O conhecimento de mercado corresponde a consciência e compreensão de informações produzidas fora do limite da firma, relacionando-se à captura de variáveis que reproduzem o fluxo circular de renda da economia, desde aquela produzida pelas unidades consumidoras, como pelas unidades produtoras e de governo. Cabe destacar, no entanto, que o conhecimento de mercado se distingue 
da mera ciência de variáveis econômicas, pois essas só se constituem conhecimento quando articuladas, revestidas de implicações lógicas.

Dada incapacidade de se processar instantaneamente todas as variáveis de mercado é razoável admitir que, por isso, as expectativas dos empresários nem sempre serão correspondidas totalmente. Ainda assim, ele, conhecendo a limitação de suas previsões, espera ser surpreendido de maneira favorável (Dillard, 1976), visto que em seu animal spirits, o empresário "procura convencer a si próprio de que a principal força motriz de sua atividade reside nas afirmações de seu propósito" (Keynes, 1936 [1996], p. 156). Nesse particular, Keynes define dois tipos de expectativas, considerando o caráter temporal dos rendimentos esperados, que são: expectativas de curto prazo (ECP) e de longo prazo (ELP). Nas ECP, o empresário volta-se para as vendas da produção proveniente dos bens de capital existentes. Essas expectativas são consideradas a partir do custo de produção e receita. Sua característica principal é o fato de o estoque de capital ser considerado constante, motivo pelo qual a trajetória recente de resultados auferidos embasa as decisões do empresário.

Diferentemente, as ELP baseiam-se na receita esperada das vendas quando ocorre uma variação na estrutura de bens de capital responsáveis pela produção, o que se caracteriza como uma expectativa de investimento. Segundo Keynes (1936 [1996], p. 156), as decisões de investimento provenientes das ELP fundamentam-se, em parte, ao montante atual de bens de capital, sobretudo, no grau de confiança "com a qual fazemos este prognóstico - na medida em que ponderamos a probabilidade de o nosso melhor prognóstico revelar-se inteiramente falso. Se esperarmos grandes mudanças, mas não tivermos certeza (...), o grau de confiança será fraco”. Para Carvalho (2015, p. 49, tradução própria), "as ELP devem ser tratadas, teoricamente, como exógenas pois podem ser e, certamente são, influenciadas pelas condições atuais, mas não determinadas por elas".

Dequech (1999a), Dequech (1999b), Romero (2014) e Crocco (2003) argumentam que o estado de ELP keynesiano é determinado por três fatores essenciais, que são: (i) conhecimento indireto; (ii) disposição otimista; e, (iii) criatividade. Porquanto, o esforço inovativo keynesiano é notadamente um 
investimento de longa duração, movido por "ativos fixos de capital, ou seja, a planta industrial e os equipamentos" (Feijó, 1993), de modo que não é possível determinar ex-ante seus respectivos rendimentos prospectivos. Isso faz com que o peso argumento seja estruturado de maneira lógica, em associação com o comportamento esperado de cada variável relevante para balizar a decisão. Nesse caso, é preciso fixar um prognóstico longitudinal para os preços de mercado (insumos e produtos substitutos), depreciação tecnológica (custo de uso), salário corrente e taxa de juros. Diante desse prognóstico, o empresário arbitrará seu grau de confiança com base em seu nível de otimismo (animal spirit), ou seja, fixará sua ELP a partir do balanceamento entre o conhecimento indireto (hipóteses racionais) e ignorância (insciência tecnológicas). Desse modo, é razoável admitir que mesmo com uma perspectiva desfavorável, as ELP podem se ser positivas, por aversão às incertezas tecnológicas (técnicas, gerenciais e de mercado).

Segundo Dequech (1999b), a criatividade, por sua vez, corresponde à capacidade racional e cognitiva que os empresários empregam para conjecturar os aspectos do futuro que são radicalmente diferentes do presente, demonstrando-se relevante na formação do grau de confiança atribuído pelos empresários às condições futuras da produção proporcionadas inovação empreendida. Desse modo, entendese que a criatividade desempenha um papel fundamental sobre a disposição otimista do empresário. Nesse caso, o conhecimento individual e de mercado se tornam vitais, pois o processo criativo dos empresários permite mobilizar habilidades adquiridas ao longo da atividade empresarial, de modo que as aprendizagens tácitas e/ou técnicas também serão utilizadas para conduzir sua aversão às incertezas tecnológicas. Em última instância, a criatividade trata-se da própria habilidade empreendedora de investir e de "interpretar" o mercado.

A partir dessa discussão é possível estabelecer uma síntese sincrônica e uma representação sistêmica da noção de conhecimento vinculada aos binômios keynesianos "probabilidade-peso do argumento" e "expectativa-estado de confiança". De modo geral, é possível afirmar que o indivíduo, inevitavelmente, se deparará com uma incerteza de caráter fundamental em qualquer que seja o curso de decisão que venha estabelecer. Habitualmente, os indivíduos respondem a este tipo 
de incerteza na sociedade por meio da probabilidade epistemológica, que se fundamenta, essencialmente, na crença racional ao peso do argumento firmado a partir de evidências empíricas e subjetivas. Essas evidências formam a base epistemológica do processo decisório, ou seja, o conjunto de conhecimentos que os indivíduos utilizam para balizar os mais variados tipos de decisão. No entanto, no âmbito da firma, a principal decisão do indivíduo é denotada pelo esforço inovativo necessário a expansão do nível de lucratividade empresarial. Por isso, o indivíduo, na figura do empresário, responderá a incerteza por meio das expectativas, dado o estado de confiança atrelado ao retorno que se espera obter pelo esforço inovativo empreendido.

Em completa aversão a incerteza, o empresário pode decidir manter o estoque de tecnologia constante, tendo o investimento financeiro como preferível, sempre que taxa de juros for mais atrativa. Em condição de otimismo, a resposta do empresário será balizada pelo conhecimento individual e de mercado, que lhe fornecerá um prognóstico temporal. Assim, o grau do esforço inovativo empresarial será determinado pelas expectativas de curto e longo prazo atreladas a Eficiência Marginal do Capital, diante do que se denomina incerteza tecnológica, resultado das expectativas sobre a técnica, o negócio e o mercado.

\section{Figura 1- Representação sistêmica dos binômios keynesianos de incerteza}

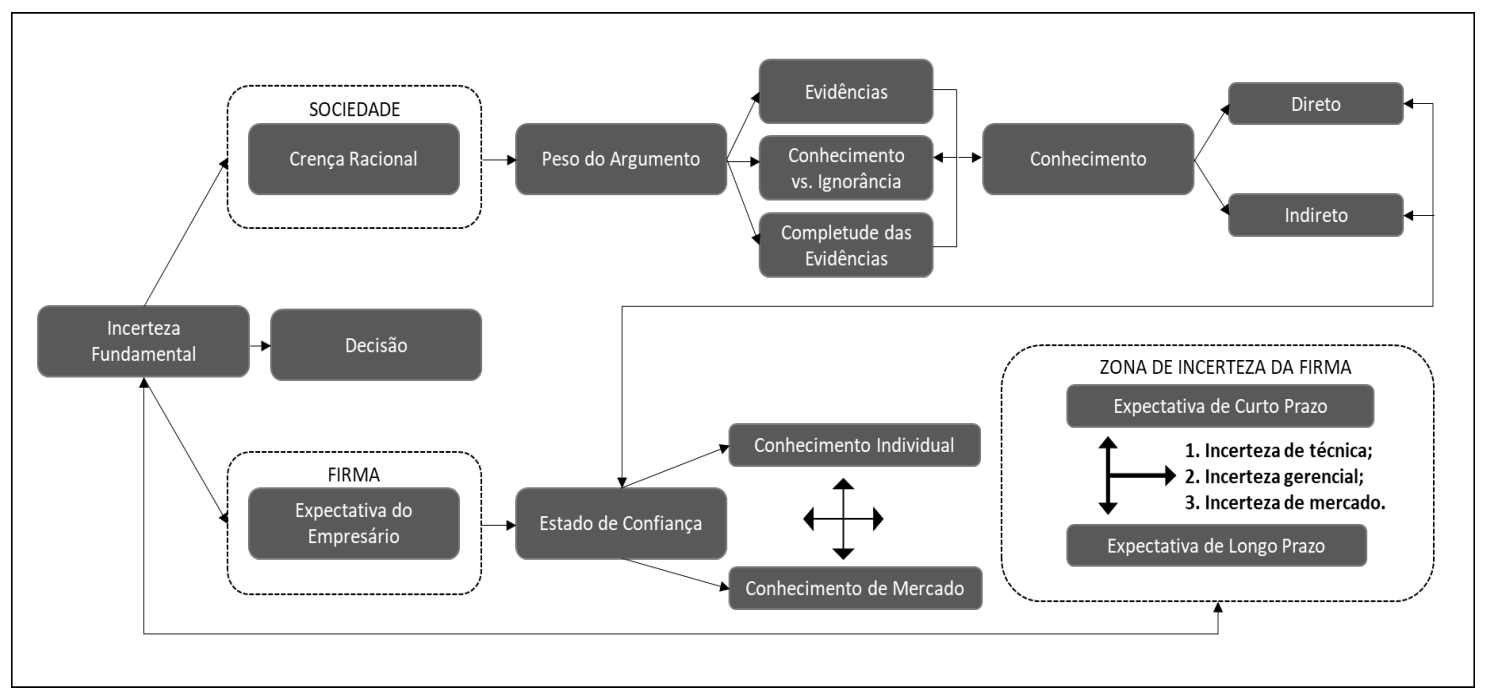

Fonte: Elaboração própria.

No entanto, a visão de firma apreendida nessa representação é estritamente simplificada, dado que em condições reais a firma não detém o lucro como objetivo 
restrito (Nelson, 2006). Desse modo, o esforço inovativo ultrapassa o investimento em bens de capital (Aidar e Terra, 2017, 2019; Feijó, 2004; Possas, 2008), de modo que o conjunto de incertezas enfrentado pelo empresário amplia-se substancialmente. Em uma perspectiva neo-schumpeteriana, por exemplo, a noção de incerteza tecnológica se expande, alterando o modo como se dá o processo de formação de expectativa dos empresários. Para tanto, faz-se necessário a compreensão epistemológica intrínseca à semântica de incerteza, expectativa e esforço inovativo em um contexto em que as decisões das firmas são dinâmicas.

\section{Inovação sob o enfoque (neo)schumpeteriano}

Nesta seção, elabora-se uma análise similar à que foi empreendida na seção anterior, com a finalidade de captar a perspectiva epistemológica intrínseca ao trinômio rotina-busca-seleção presente na semântica neo-schumpeteriana de incerteza, expectativa e esforço inovativo. Por isso, o tratamento dado a firma receberá uma dimensão evolutiva, pautada na tese de que as firmas buscam realizar lucros positivos, mas não necessariamente lucros máximos. Esse argumento remota a hipótese de seleção natural oriundo da biologia evolucionista, inicialmente aproximado à Ciência Econômica por Alchian (1950) e Enke (1951) para explicar os mecanismos da concorrência empresarial, tendo substituído o princípio neoclássico da otimização da função de produção e de custo pelo argumento evolucionário de prevalência, que definem como sendo as estratégias competitivas pelas quais as firmas buscam a permanência no mercado. Mais tarde, Friedman (1953) e Becker (1962) utilizaram a concepção de seleção natural para esboçar uma crítica ao suposto comportamento maximizador de lucros da firma, de modo que transportaram a discussão do comportamento competitivo para um contexto não atômico.

Apesar disso, o efetivo desenvolvimento teórico da abordagem evolucionária só ocorre na segunda metade no século XX, sob duas contribuições específicas. De um lado, têm-se o trabalho The Economics of Industrial Innovation, em que Freeman (1974) resgata o estudo de ciclos econômicos desenvolvido por Schumpeter, utilizando-o para fundamentar sua demonstração de que a inovação encontra-se no cerne dos movimentos cíclicos da economia capitalista. De outro lado, inspirando-se 
na teoria darwinista da evolução, Nelson e Winter (2005), em 1982, propuseram a incorporação da inovação ao referencial analítico da teoria da firma através do livro "Uma Teoria Evolucionária da Mudança Econômica", em que os autores tratam a dinâmica do comportamento empresarial sob os conceitos darwinistas de seleção, adaptação e herança.

Para Nelson e Winter (1977, p. 36, tradução própria) uma teoria da inovação deve incorporar explicitamente a natureza estocástica da inovação, de forma a considerar a diversidade e complexidade organizacional como elementos preponderantes para o processo inovativo. Isso porque a "inovação envolve incerteza de uma forma fundamental". Na semântica desses autores, a inovação consiste em um fenômeno social e, logo, não estritamente econômico. Trata-se de mudanças não triviais no produto ou processo produtivo sem qualquer precedência, envolto a um processo contínuo de desequilíbrio. Portanto, o esforço inovativo em direção a uma mudança substancial de produto ou processo envolve um grau de incerteza considerável, que abrande desde o processo de elaboração que antecede o lançamento no mercado, como o período que se sucede. Isso porque o processo de desenvolvimento inovativo permite a coexistência de esforços tecnológicos desconhecidos ou mesmo reacionários a mudança introduzida no mercado, fato que sustenta a persistência de desequilíbrios no processo produtivo e concorrencial.

De acordo com Possas (1988), o esforço inovativo das firmas geram impacto direto sob o modo como o mercado se desenvolve ao longo do tempo, em decorrência do caráter eminentemente dinâmico da inovação, o que situa a incerteza como um aspecto central da teoria da inovação neo-schumpeteriana. A noção de incerteza contida em Nelson e Winter (1977) é abstraída em dois níveis: individual, própria do empresário; e, exploratória, no nível da firma, relativa ao procedimento de busca heurística por soluções de mercado. Isso porque o esforço inovativo não se restringe à expansão da capacidade produtiva ou à aquisição de bens de capital que alterem uma função de produção passível de otimização, mas abarca um grande conjunto de projetos capazes de gerar conhecimento e aprendizado.

Assim, conforme destaca Simon (1987, p. 14, tradução própria), "explicar o comportamento decisório [do empresário] em circunstâncias dinâmicas e complexas 
que envolvem uma grande dose de incerteza" exige mais do que premissas de otimização. Porquanto, a efetividade do resultado do esforço inovativo do empresário será determinada por sua capacidade de coletar, sistematizar e compreender informações úteis para a formulação de cursos decisórios. No entanto, diante da racionalidade limitada dos agentes, torna-se inexequível prever, irrestritamente, o resultado de seu esforço inovativo.

No tocante a este aspecto, a incerteza da inovação pode ser definida como a indeterminação do resultado da busca por novas trajetórias tecnológica, dentre às inúmeras alternativas possíveis, onde a racionalização é utilizada como critério de ponderação, responsável por: i) listar as decisões possíveis; ii) estimar as consequências de cada alternativa de investimento em inovação, sob a forma de distribuição de probabilidades; e, iii) a comparação dessas alternativas por meio dos conjuntos de consequências que lhes foram atribuídos, a partir de payoffs prédefinidos (Simon, 1978).

Nessa perspectiva, o conhecimento é um elemento essencial para a consecução do esforço inovativo. Em termos semânticos, o conhecimento refere-se a compreensão sistemática de informações, mas que se demonstra incompleto e impreciso, quando se trata de distribuições de probabilidades futuras, dado os limites cognitivos dos indivíduos. Diante dessa premissa epistemológica, inerente ao modelo de racionalidade de Simon (1987), Nelson e Winter (1977) afirmaram que uma decisão coerente atrelada ao esforço inovativo exige dos empresários um raciocínio pautado em um processo exploratório de busca, dado que o fluxo de inovações altera constantemente o conjunto de informações na qual os empresários balizam suas decisões, o que reforça a complexidade de suas escolhas. Esse processo de busca expressa-se por um conjunto de procedimentos para identificar, rastrear e localizar maneiras promissoras de sustentar o esforço inovativo, que forneça uma certa distribuição de probabilidade condicional de inovações (ou características de inovação), dadas as condições de apropriabilidade do conhecimento enfrentadas no interior da firma.

Nessa abordagem, os projetos de Pesquisa \& Desenvolvimento (P\&D) revestem-se de relevância. Porquanto, constituem-se em um mecanismo de 
sistematização de informação e ampliação do estoque de conhecimento mobilizado pela firma, tanto para subsidiar o processo de geração ou modernização de produto e processo, como para permitir o gerenciamento dos riscos empresariais, em termos de custo, demanda e concorrência. A partir do $\mathrm{P} \& \mathrm{D}$, as firmas desenvolvem uma sequência de rotinas de curto e/ou longo prazo para as suas distintas decisões, que podem ser dinâmicas ou estáticas, ou seja, decorrentes de novas aprendizagens ou invariantes e associadas ao estoque de capital.

Segundo Dosi (1988), as rotinas vinculadas à P\&D permitem a apreensão de conhecimentos, que, por sua vez, contribuem para a formação de expectativas positivas com relação ao processo decisório das firmas quanto ao esforço inovativo, uma vez que fortalecem a confiança na inovação pretendida pelo empresário. Da semântica de rotina, infere-se a existência de dois tipos particulares de conhecimento: tácito e codificado. De forma geral, o conhecimento tácito refere-se ao aprendizado baseado na experiência, geralmente associado à trajetória tecnológica da firma. Tratase de um conhecimento baseado nas rotinas de curto prazo, no que se refere à atividade produtiva. Por outro lado, o conhecimento codificado mobiliza um conjunto de informações complexas, sejam elas de fonte interna ou externa, geralmente sofisticados e disruptivos.

Os neo-schumpeterianos apontam a construção desse tipo de conhecimento como essencial para o desenvolvimento de paradigmas tecnológicos, que defendem ser viabilizado, em grande medida, pelos investimentos em $\mathrm{P} \& \mathrm{D}$ responsáveis por codificar o conhecimento, permitindo que este seja transmitido, manipulado, armazenado e reproduzido. É, portanto, o esforço inovativo, segundo os neoschumpeterianos, um conjunto de estratégias competitivas no qual a firma visa realizar lucros positivos, tais como: P\&D interno e externo, desenvolvimento \& engenharia (D\&E), aquisição de conhecimentos externos (consultorias técnicas, por exemplo), marketing, treinamento de pessoal e o habitual esforço para à aquisição de máquinas e equipamentos.

Esse processo de apreensão do conhecimento em forma de esforço inovativo converge para a noção de adaptação e herança genética transposta para a análise econômica, pois determinará o percurso necessário à sobrevivência das firmas. Nesse 
particular, entende-se que a busca e a sistematização das rotinas contribuem para mitigar as incertezas do processo inovativo, mas não as eliminam por completo. Isso porque os resultados dos esforços de P\&D dependem de uma etapa de posterior, que seleciona as inovações que serão difundidas, consonante com a última fase do processo criativo psíquico e econômico. De acordo com Nelson e Winter (2005), o lócus preferencial de seleção das inovações decorrentes do esforço inovativo das firmas ocorre no mercado, mas também é exercido por agências reguladoras e normas institucionais, que condicionam a trajetória das inovações disseminadas pelas firmas. Isso inclui as preferências dos consumidores, as estratégias de diferenciação dos concorrentes e a legislação setorial.

A fase de seleção determina o ritmo de difusão da inovação, que poderá seguir um mesmo regime tecnológico (Freeman; Soete, 1997), fundamentando-se em mudanças técnicas residentes em uma trajetória tecnológica já selecionada e difundida no mercado (Nelson e Winter, 2005); ou promover mudanças radicais, que resultem em rupturas e descontinuidades no paradigma tecnológico vigente no ambiente de seleção (Giovanni e Dosi, 1988). Freeman e Soete (1997) fragmentam a concepção de inovação, diferenciando-a em inovação incremental e radical. A partir dessa perspectiva, Dosi (1988) utiliza as definições de paradigma tecnológico e trajetória tecnológica para demarcar essas definições. Um paradigma tecnológico consiste em oportunidades tecnológicas para o desenvolvimento de inovações e suas formas de exploração, enquanto a trajetória tecnológica representa a direção da inovação, em termos de semelhanças e regularidades, determinando o regime tecnológico seguido pela tecnologia em um paradigma tecnológico.

Nesse particular, inovações incrementais são definidas como as mudanças tecnológicas que seguem uma determinada trajetória tecnológica, ou seja, que mantém um modelo ou um mesmo padrão de soluções de problemas tecnológicos aplicáveis ao segmento produtivo ou à atividade econômica em geral. Por sua vez, as inovações radicais correspondem ao tipo de inovação que rompe as trajetórias tecnológicas existentes, inaugurando uma nova rota tecnológica e, portanto, um novo paradigma. Uma inovação incremental representa melhorias no arcabouço 
tecnológico, nas técnicas de produção ou bens de capital, enquanto as radicais são os saltos descontínuos em um regime técnico.

Dosi, Tyson e Zysman (1989) explicam que a incerteza que permeia os investimentos em inovação não ocorre somente pelo caráter seletivo dos mercados, mas, principalmente, pelo fato de novas trajetórias tecnológicas não terem seus desdobramentos e adequações determinados em um contexto ex-ante. No contexto competitivo, uma nova trajetória tecnológica inserida no mercado por um concorrente pode neutralizar a estratégia adaptativa da empresa, ao passo que sua inovação pode tornar-se obsoleta rapidamente. De acordo com Dosi (1988, p. 1227, tradução própria) "o sucesso de inovações futuras depende, fundamentalmente, das decisões de investimento assumidas (no presente) por todas as firmas do mercado, visto que essas tendem a não cooperar tecnologicamente". Dessa maneira, a incerteza associada à inovação amplia-se à medida que a seleção natural dos mercados conduz as firmas rivais a decisões de investimentos autônomas e distintas. Como resultado desse processo, ocorre assimetrias técnico-econômicas consistentes entre firmas, setores, países e mesmo ao longo do tempo.

Segundo Dosi (1988) essas diferenças setoriais em nível da firma explicitam-se em virtude do tipo de inovação - produto, processo, marketing ou organizacional. Nelson (2006) acrescenta que a principal fonte dessa diferença está relacionada ao grau de apropriabilidade do conhecimento, que resulta no desenvolvimento de aptidões dinâmicas e organizacionais que possibilita integrar o esforço inovativo às diferentes divisões internas da firma. Nessa perspectiva, Malerba (1992) elabora três proposições fundamentais: a) a aprendizagem é um processo dispendioso e endógeno às diferentes divisões internas da firma (produção, engenharia, P\&D, financeiro e marketing); b) a aprendizagem está ligada às diferentes fontes de conhecimento, interna ou externa; e, finalmente, c) a aprendizagem é um processo cumulativo, que tende à aumentar o estoque de capacidades dinâmicas.

Nesse particular, Dosi, Fagiolo e Roventini (2010) ressaltam que o arcabouço tecnológico das firmas apresenta heterogeneidade, o que conduz a decisões de investimentos diferenciadas. Isso porque o nível de investimento direcionado ao estoque de capital e a inovação correspondem a uma estratégia adaptativa, por meio 
da qual as firmas buscam preservar-se no mercado. Consequentemente, a inovação resultante de estratégias adaptativas focadas nos investimentos em estoque de capital apresenta descontinuidades no tempo, refletindo em instabilidade no sistema econômico, alternando períodos de crise e crescimento. De acordo com Baptista (1997), a abordagem evolucionária de inspiração neo-schumpeteriana postula que as estratégias adaptativas impõem às firmas um conjunto de decisões complexas sempre que acionam investimentos orientados à sua capacidade instalada ou a uma nova trajetória tecnológica. Ademais, as firmas operam em contextos setoriais específicos, os quais operam como condicionantes do esforço inovativo.

Os autores Winter (1984), Cohen e Levinthal (1989) e Malerba e Orsenigo (1997) tratam da importância de especificidades na base de conhecimento das firmas para o surgimento desses regimes tecnológicos e de padrões setoriais. Inicialmente, Winter (1984) afirma que as duas visões schumpeteriana de inovação - destruição criativa (Schumpeter, 1911 [1997]) e acumulação criativa (Schumpeter, 1942 [2016]) - podem ser associadas a diferentes regimes tecnológicos. Sob a perspectiva de ruptura e descontinuidade, a indústria tende a abrigar uma gama de inovações radicais, em grande medida, promovidas por firmas entrantes, visto a ausência de significativas barreiras à entrada impostas pelo regime em vigor. Contudo, sob a perspectiva de continuidade e cumulatividade, a indústria tende a configurar-se a partir de inúmeros padrões tecnológicos, visto que a diferenciação de produtos/processos acirrara a competição setorial e potencializa a incerteza inovativa.

Diante desses elementos teóricos, torna-se exequível uma síntese sincrônica e uma representação sistêmica da noção de conhecimento vinculada ao trinômio busca-rotina-seleção, retratado a partir do esforço inovativo, sob condição de incerteza (Figura 2). Em uma economia dinâmica, em que o processo de destruição criativa promove permanentes fluxos de desequilíbrio nos mercados, a prevalência das firmas será determinada pela capacidade de essas contornarem às incertezas do esforço inovativo e à competição tecnológica. Dado que os desequilíbrios provocados pelo processo de destruição criativa são cumulativos e constantes, o 
empresário enfrenta uma incerteza de caráter fundamental, de modo que o retorno do investimento inovativo não será assegurado ex-ante.

\section{Figura 2 - Representação sistêmica da incerteza neoschumpeteriana}

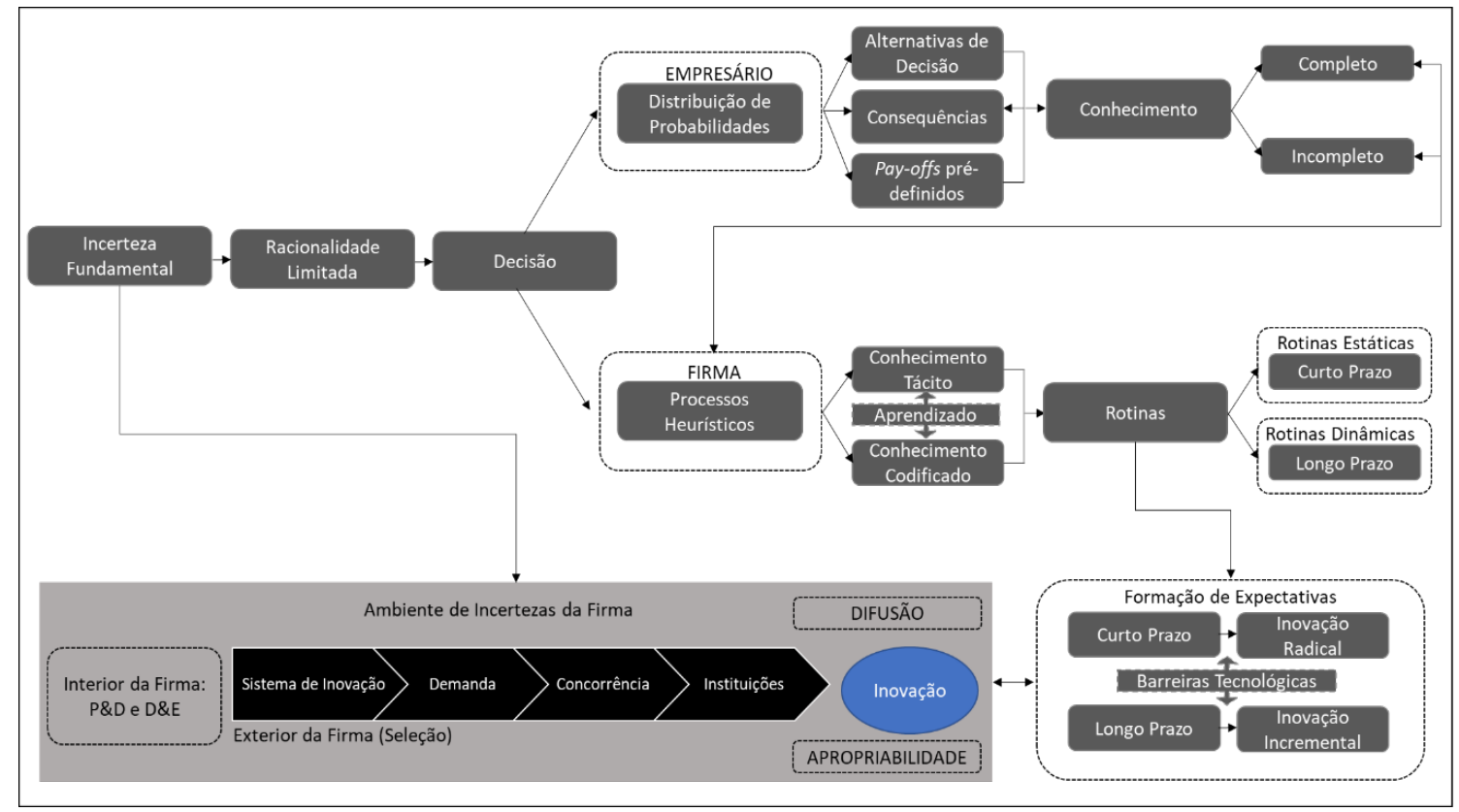

Fonte: Elaboração própria.

Sob a perspectiva neo-schumpeteriana, a incerteza fundamental encontra-se associada com a racionalidade limitada, que imputa aos indivíduos a incapacidade de maximizar suas decisões com base no estoque de conhecimento disponível, de sorte que não conseguem inferir um curso decisório ótimo a partir dos parâmetros conhecidos. No âmbito do processo inovativo, os indivíduos respondem a este tipo de incerteza por meio de dois núcleos de decisão - probabilístico e heurístico. No núcleo probabilístico, o indivíduo, na figura do empresário, fixa suas decisões com base de uma distribuição de probabilidade, condicionada a uma série de alternativas de decisões, as quais atrelam a si uma série de consequências (retorno esperado e implicações positivas e/ou negativas). Quanto mais completa às informações sobre essas consequências, melhor é a condição de racionalização das decisões individuais, ou seja, maior será a probabilidade de satisfação. Isto é, o empresário assumirá uma decisão, cuja recompensa se aproximará do esperado.

Portanto, são as informações que formam a base epistemológica do processo decisório do empresário neo-schumpeteriano, ou seja, o conjunto de conhecimentos 
que os indivíduos utilizam para ranquear suas alternativas de decisão. Em uma perspectiva endógena ao empresário, o conhecimento poderá ser completo, de modo que seja possível absorver a totalidade de informações necessárias para fixar o nível do esforço inovativo. Assim, é razoável admitir que todas as informações que dizem respeito à sua própria capacidade de investimento serão conhecidas. No entanto, a incapacidade do empresário de mapear e explorar todo o leque de alternativas disponíveis, bem como suas respectivas consequências, lhe expõe a uma incerteza procedimental, o que resulta em um estoque de conhecimento incompleto. Nesse sentido, o processo de decisão transporta-se para o núcleo heurístico, no interior da firma, pelo qual os empresários buscam mitigar a incerteza procedimental, contornando os riscos inerentes ao processo inovativo, tanto em termos de custo, como de desenvolvimento científico, adequação técnica e mecanismos de produção.

$\bigcirc$ processo de busca assenta-se em uma base epistemológica constituída por processos de aprendizado internos e externos à firma, advindos do processo produtivo (learning by doing), da utilização de bens de capital (learning by using), da absorção de desenvolvimentos gerados pelo sistema (inter)nacional de ciência e tecnologia, da imitação ou incorporação de tecnologias e processos intersetoriais, do P\&D interno ou da cooperação com outros atores do sistema de inovação, como fornecedores e clientes. A partir desses processos de aprendizado, os empresários utilizam-se do conhecimento tácito e codificado gerado no interior da firma para fixar rotinas compatíveis com as recompensas definidas por meio da distribuição de probabilidades condicionais. Assim, firmam-se expectativas de curto e longo prazo, associadas, respectivamente, ao tipo de inovação - incremental ou radical. As expectativas serão positivas, tanto quanto, a base de conhecimento e os processos aprendizados permitirem superar às barreiras tecnológicas.

processo de formação de expectativas da firma ocorre dentro de um ambiente de incerteza fundamental, composto pelos departamentos de P\&D e D\&E - no interior da firma - e pelo ambiente de seleção, exterior à firma. Nesse caso, as expectativas do esforço inovativo formam-se sobre a probabilidade de as atividades de pesquisa fornecerem elementos técnicos e econômicos para a implementação de inovações. No entanto, a efetividade dessas inovações depende de diversos 
mecanismos de seleção. Isso porque durante o processo de pesquisa interno à firma, é possível a coexistência de novas tecnologias ou de mudanças na trajetória tecnológica em que a firma opera. Aliado a isso, condicionantes setoriais podem alterar substancialmente as especificidades do regime tecnológico do setor em que a firma está inserida, podendo, em uma condição extrema, tornar obsoletos os resultados do esforço inovativo interno. Logo, quanto mais a base de conhecimento e aprendizado da firma for alinhada ao sistema (inter)nacional de inovação, maior será a segurança dos empresários para realizar investimentos no esforço inovativo.

A representação epistemológica da relação entre incerteza, expectativa e esforço inovativo extraída da abordagem neo-schumpeteriana demonstra-se mais ampla, quando comparada com a representação apreendida na semântica keynesiana. Não obstante, fundamenta-se em uma visão microevolutiva do processo decisório, de modo que negligencia o setor financeiro como elemento delineador do esforço inovativo (Dabic et al., 2011). Segundo Hodgson (1998), em uma economia dinâmica, a incerteza não restringe-se aos eventos futuros em si, mas também sobre as oportunidades disponíveis aos objetivos do empresários. Nesse particular, conforme aponta Possas (2008, p. 68), é relevante incorporar "um conjunto mais complexo de elementos financeiros, incluindo aplicações de curto prazo e respectivas taxas de retorno, liquidez desejada, lucros retidos, taxas de juros dos débitos [...]" para demarcar como a incerteza e as expectativas afetam o esforço inovativo das firmas no curto e longo prazo. Para tanto, faz-se necessário uma aproximação ontológica entre essas duas abordagens.

\section{Proximidades teóricas entre as abordagens}

Na teoria keynesiana, a inovação é tratada como um fator exógeno ao sistema econômico, diferentemente da ênfase dada pela abordagem neo-schumpeteriana, em que a inovação corresponde a um elemento inexorável e endógeno ao próprio sistema capitalista. Por essa razão, os economistas neo-schumpeterianos consideram a inovação como uma oportunidade de negócio, operacionalizada pelas firmas como forma de elevar as receitas e, simultaneamente, como estratégia concorrencial de adaptação e sobrevivência no mercado. Este entendimento coloca em evidência a 
principal distinção entre as duas teorias no que se refere ao esforço inovativo, porquanto os neo-schumpeterianos consideram que o conhecimento tecnológico é assimétrico, não estando disponível às firmas na mesma proporção, aspecto não considerado por Keynes, mesmo quando tratou indiretamente o tema no capítulo 11 da TG.

Dessa distinção, porém, pode-se observar aproximações entre as duas abordagens. Na TG, investimentos em bens de capital - considerado pelos neoschumpeterianos como o principal arcabouço tecnológico das firmas - poderão ampliar as receitas, ao mesmo tempo que contribuem para a redução dos custos de produção, potencializando, dessa maneira, a eficiência marginal do capital empregado na atividade. Infere-se, portanto, que o esforço inovativo keynesiano é estimulado por ganhos efetivos nos rendimentos da produção. Por sua vez, a abordagem neo-schumpeteriana trata a inovação como reflexo das estratégias adaptativas das firmas, que são pautadas em investimentos destinados ao desenvolvimento de novos produtos, métodos de produção ou de comercialização, os quais derivam-se da absorção de oportunidades tecnológicas inerentes a trajetória desenvolvimento tecnológico em vigência no mercado.

Para os neo-schumpeterianos, a modernização dos estoques de capital não apenas amplia os rendimentos prospectivos do empresário, ou seja, "a série de anuidades de quase-rendas que se espera obter da venda da produção advinda da alocação dos bens de capital durante a sua vida útil”, como postula Keynes (1936 [1996], p. 120), mas inaugura outras possibilidades de rendimentos, devido à alteração das trajetórias tecnológicas, ou mesmo do estabelecimento de novos padrões de consumo, quando as inovações tornarem-se tão radicais ao ponto de introduzirem no mercado novos paradigmas tecnológicos (Crocco, 2003). Entretanto, é importante destacar que em ambas as teorias, a incompletude do conjunto de informações disponíveis no mercado, seja a respeito da conjuntura econômica ou do conhecimento tecnológico disponível, impõem ao empresário incertezas quanto ao resultado de seu esforço inovativo, impossibilitando prever se suas expectativas serão confirmadas, por mais otimistas que elas possam parecer. 
Nesse particular, vislumbra-se uma certa compatibilidade epistemológica entre os conceitos de incerteza, expectativa e esforço inovativo keynesiano e neoschumpeteriano. Em termos de decisões relacionadas à inovação, a incerteza perene de ambas as abordagens assume caráter fundamental pela limitação do conhecimento, incompleto segundo Keynes (1926) e impreciso na perspectiva de Nelson e Winter (1977 e 2005). Em uma inferência ontológica, entende-se que mitigar a incerteza do processo inovativo, seja ele a partir do investimento em bens de capital ou em P\&D, requer uma compreensão distinta das relações lógicas relevantes entre as evidências que circundam o empresário. Em uma interpretação ontológica semelhante, a formação de expectativas sobre o retorno do investimento, isto é, do esforço inovativo (aquisição de conhecimento), dependerá do alcance temporal das informações capturadas pelos empresários. Nesse particular, a relação filosóficametodológica entre o grau do resultado do esforço inovativo - incremental ou radical - dependerá do limiar heurístico e do peso do argumento (rotinas).

Existem dois elementos essenciais que podem ser explorados na articulação entre o conceito de incerteza inserido no pensamento de Keynes e neoschumpeteriano. Conforme apresentado nas seções anteriores, a interpretação neoschumpeteriana acerca da incerteza relativa à confiança com que os investimentos em inovação são realizados possui duas fontes distintas. Primeiramente, destaca-se que o empresário se depara com um conjunto de informações insuficientes para realizar previsões sobre a adequação das inovações pretendidas para o alcance de vantagem competitiva no contexto concorrencial, além do fato da incompletude e da racionalidade limitada. Ao mesmo tempo, a incompletude das informações disponíveis aos empresários impossibilita prever se a produção adicional advinda da inovação será acompanhada por uma demanda que viabilize a realização de lucros extraordinários. Comparando essa fonte de incerteza ao pensamento de Keynes, verifica-se uma proximidade teórica com o conceito de peso do argumento, proposto no TP. Como visto na seção dois, Keynes (1921) indica que o peso do argumento encontra-se associado à quantidade de evidências relevantes para elaborar conclusões lógicas, ou mesmo previsões consistentes. Portanto, a primeira fonte de incerteza discutida pelos neo-schumpeterianos alude a um problema de baixo peso 
de argumento no curso da tomada de decisão de investimento inerentes ao esforço inovativo.

A segunda fonte de incerteza relacionada a introdução de uma inovação corresponde ao conhecimento necessário para se promover a inovação. Uma inovação incremental e o surgimento de novas trajetórias tecnológicas decorre de um conhecimento preexistente, enquanto para o surgimento de novo paradigma tecnológico provém de um conhecimento completamente novo, originado por inovação radical. Assim, "o processo de tomada de decisão relacionado à introdução de uma inovação radical ou incremental será diferente, conforme o papel desempenhado pelo conhecimento prévio" mobilizado pelo empresário (CROCCO, 2003, p. 511). Dosi, Fagiolo e Roventini (2010), por exemplo, distinguem o conhecimento em tácito e codificado. Essas terminologias ajustam-se a noção de conhecimento direto e indireto de Keynes (1921), conforme Quadro 1.

Quadro 1 - Comparação trilateral entre conhecimento tácito-codificado, indiretodireto e inovação

\begin{tabular}{|c|c|c|c|c|}
\hline \multirow{5}{*}{ 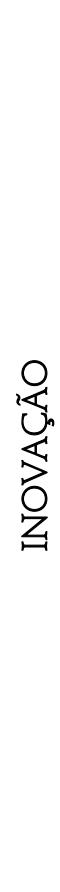 } & \multirow[b]{3}{*}{ 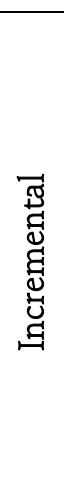 } & \multicolumn{3}{|c|}{ Conhecimento } \\
\hline & & & Direto & \\
\hline & & Tácito & $\begin{array}{l}\text { Decorre das experiências (dos empresários) } \\
\text { Faz uso dos sentidos (dos empresários) } \\
\text { Baseia-se na percepção (dos empresários) } \\
\text { Desenvolve-se no curto prazo }\end{array}$ & $\begin{array}{l}\text { 岂 } \\
\text { 苨 } \\
\text { 兒 }\end{array}$ \\
\hline & & & Indireto & \\
\hline & 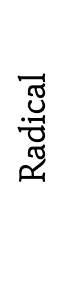 & Codificado & $\begin{array}{l}\text { Mobiliza informações complexas (do mercado e da firma) } \\
\text { Estrutura-se logicamente } \\
\text { Gera conclusões a partir dos conhecimentos já adquiridos } \\
\text { Desenvolve-se no longo prazo }\end{array}$ & 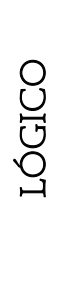 \\
\hline
\end{tabular}

Fonte: Elaborado própria.

De maneira simplificada, a comparação proposta no Quadro 1 busca sintetizar as semelhanças existentes nos conceitos de conhecimentos tácito e codificado (de origem neo-schumpeteriana) e de indireto e direto (derivado da TP de Keynes), 
relacionando-as com a inovação. $O$ esforço inovativo empreendido pelas firmas para promover mudanças tecnológicas menos disruptivas, ou seja, inovações de produto ou processo baseadas no aperfeiçoamento tecnológico, exige uma heurística menos complexa, pois o processo inovativo baseia-se em conhecimentos já absorvidos pela firma. Uma inovação incremental assenta-se em uma trajetória tecnológica em que a firma já opera. Desse modo, o esforço inovativo depende de decisões anteriores ou experiências feitas no passado (BURLAMAQUI; PROENÇA, 2003), de modo que a incerteza alinha-se a path dependence.

Nesse particular, observa-se que a inovação incremental se baseia no conhecimento existente, o que remente à compreensão da firma como lócus de experimentação. Portanto, o conhecimento mobilizado decorre, essencialmente, das experiências dos empresários, os quais fazem uso dos sentidos e do animal spirits para fixar o peso do argumento de suas alternativas de decisão. Trata-se de um conhecimento baseado nas habilidades e competências adquiridas pela firma por meio dos processos de aprendizagem de menor sistematização (learning by doing e learning by using). Logo, a heurística decisória utiliza-se de evidências de baixa completude para formar o peso do argumento (Figura 1).

Por se tratar de inovações aderentes a uma trajetória tecnológica já em curso, a incerteza do processo inovativo tende a reduzir-se, no que se refere-se ao ambiente de incerteza externo à firma (Figura 2), pois contorna-se os mecanismos de seleção atribuídos ao sistema (inter)nacional de inovação e/ou institucional, o que reforça o estado de confiança do empresário. No entanto, preserva-se às incertezas referentes aos mecanismos de seleção atribuídos ao mercado, tanto em relação aos consumidores, como em relação aos concorrentes, uma vez que mudanças tecnológicas dentro de uma mesma trajetória se sujeitam à simultâneas e contínuas estratégias de diferenciação por parte das concorrentes. Esse aspecto reforça a competição tecnológica entre as firmas, que buscam atrair os consumidores por meio inovações organizacionais e de marketing, para além do produto.

Portanto, o esforço inovativo baseado no desenvolvimento contínuo de uma trajetória tecnológica fornece ao empresário informações capazes de subsidiar adaptações no estoque de capital. Isso porque a experiência acumulada permitirá 
que as decisões de investimento sejam balizadas com um maior grau confiança. Porquanto no curto prazo as decisões de investimento em inovação são satisfeitas pelo conhecimento que o empresário consegue mobilizar acerca da trajetória tecnológica, o que, no geral, impõe uma temporalidade de curto prazo para as expectativas associadas à inovação incremental.

Por outro lado, as inovações radicais caracterizam-se por um esforço inovativo mais disruptivo, responsável por romper com a trajetória tecnológica vigente no setor, promovendo um impacto significativo sobre a estrutura de mercado, em direção a uma mudança de paradigma tecnológico. Trata-se de uma inovação centrada no impacto das inovações, em oposição a perspectiva de "grau de novidade incremental". Desse modo, a heurística de aprendizagem das firmas baseiam-se em conhecimentos complexos, que ultrapassam "a descoberta cumulativa de informações pré-existentes" (Hodgson, 1998, p. 68, tradução própria). Nesse caso, o processo decisório parte de uma incerteza procedimental sobre o desempenho da inovação radical projetada e, portanto, não se baseia por meras estimativas de probabilidade subjetiva à luz dos dados conhecidos.

As decisões de investimento dessa natureza dependem de estruturas cognitivas sofisticadas, capazes de articular o conhecimento individual e de mercado do empresário (Figura 1), por meio da conjunção do conhecimento tácito e codificado (Figura 2). Assim, os empresários, por meio da firma, irão estruturar as alternativas de investimento com base em rotinas, ou seja, estruturas lógicas de decisão. Essas estruturas lógicas de decisão ajudarão a mitigar as incertezas técnicas, gerenciais e de mercado Keynes (1921 e 1996) relativas aos mecanismos de seleção externos à firma Nelson e Winter (1977 e 2005).

Sumariamente, os investimentos em inovações radicais demonstram-se mais sensíveis as ELP dos empresários, visto que mudanças no paradigma tecnológico exigem um conhecimento tecnológico mais apurado que, naturalmente, só será alcançado através do contínuo desenvolvimento da trajetória tecnológica, isto é, da constante inovação incremental do estoque de capital fixo e do avanço dos spillovers decorrentes de P\&D. Isso porque as inovações incrementais são desenvolvidas com o estoque de capital fixo existente, ao passo que as inovações radicais só podem ser 
viabilizadas com um novo estoque de capital, logo, mais investimentos em bens de capital, treinamento, marketing, engenharia e aquisição de conhecimentos codificados externos. Têm-se como alternativa para as ELP a adoção de estratégias adaptativas de $\mathrm{P} \& \mathrm{D}$, com as quais os empresários poderão ampliar o nível de conhecimento tecnológico e, dessa forma, minimizar o risco de se investir em inovações radicais. $\bigcirc$ resultado das ações de P\&D fornecerá evidências e parâmetros capazes de aumentar e/ou melhorar o peso do argumento no qual está firmada a ELP do empresário, quando busca migrar em direção a outro paradigma tecnológico.

Nesse particular, os autores neo-schumpeterianos ressaltam a concepção de empreendedorismo tecnológico, que se refere à disposição do empresário em direcionar investimentos para o desenvolvimento de novos paradigmas tecnológicos, minimizando as incertezas das inovações radicais e subsidiando a criação de bens sem substitutos próximos, mas com forte apelo ao consumo. Em comparação com o pensamento de Keynes, o empreendedorismo tecnológico pode ser associado pelo animal spirits postulado na TG, em que o empresário, mesmo sob forte incerteza, direciona investimentos na introdução de um novo paradigma tecnológico no mercado, esperando elevar suas receitas, mas, sobretudo, diminuir o posicionamento dos seus concorrentes perante os seus consumidores. Finalmente, conclui-se que as incertezas se demonstram insuperáveis no processo decisório, podendo ocorrer em maior ou menor grau, em decorrência do conhecimento dos empresários. Por isso, as decisões de investimentos sempre serão balizadas pelas ECP e ELP, além da propensão ao risco que o "espírito empreendedor" esteja disposto a assumir na busca por novas trajetórias tecnológicas ou paradigmas tecnológicos.

Em resumo, observa-se que o peso do argumento atrelado as inovações incrementais e, consequentemente, aos ajustes nos preços e na produção durante a vida útil do investimento materializado em esforço inovativo, bem como o estado de confiança vinculado as inovações radicais, demonstram-se sensíveis a eficiência marginal do capital ${ }^{1}$. Isso porque o investimento flutuará até o ponto da curva de

\footnotetext{
${ }^{1}$ Utiliza-se a abstração de que o capital é epistemologicamente sincrônico ao esforço inovativo: bens de capital, capacidade produtiva, estrutura de P\&D, D\&E, propriedade intelectual, entre outros. Para detalhes consultar (Malerba, 2005).
} 
demanda de investimento em que a eficiência marginal do esforço inovativo seja equivalente à taxa de juros do mercado (KEYNES, 1996). Nesse sentido, Aidar e Terra (2017, p. 33) destacam que o volume de investimento é dado "pelo confronto da eficiência marginal do capital com a taxa de juros, [...] pelo qual o empresário buscará mensurar os custos de oportunidade entre ativos mais líquidos, remunerados pelas taxas de juros e os menos líquidos - de capital - [...] esperado".

Não obstante, ainda que a eficiência marginal do capital seja superior aos rendimentos dos ativos remunerados pela taxa de juros vigente, outro elemento é capaz de afetar a decisão de investimento ligada ao esforço inovativo do empresário - a inflação. Segundo Feijó (1993a, p. 1278) uma "inflação permanente e com altas taxas, [...] tem um efeito deletério sobre o funcionamento da economia, na medida em que aumenta o conflito social, provocando uma cadeia de reações entre os agentes econômicos que desejam proteger suas rendas", o que inclui o empresário. Em um cenário inflacionário, as expectativas quanto ao valor futuro da série de rendimentos esperados para a nova tecnologia não dependerão exclusivamente da demanda de mercado, mas também dos custos relativos da tecnologia absorvida à firma na forma de esforço inovativo. Nesse sentido, os ganhos eventuais decorrentes da inovação podem ser neutralizados pelos choques inflacionários, incorrendo na redução do mark-up das firmas (Eichner, 1985).

Existem várias contribuições pós-keynesianas relevantes para explicar o papel da dinâmica monetária e do sistema financeiro sobre a inovação e, portanto, não há intenção de retomar este debate (Christensen, 1992; Crocco, 1999; Crocco, 2008; Minsky, 1986; O’Sullivan, 2005; Perez, 2020). A ênfase aqui se dá sobre a asserção de que o sistema financeiro corresponde a um quinto mecanismo de seleção, para além do sistema de inovação, dos consumidores e concorrentes (mercado) e das instituições (normas e regulamentações). Diante da abordagem suscitada por Keynes (1996) sobre o processo de formação de capital, bem como na perspectiva de financiamento da atividade inovativa proposta por Schumpeter (1997), a provisão monetária é um elemento preponderante para a consecução dos investimentos em esforço inovativo. De acordo com (Carvalho, 1997, p. 471), o processo de investimento começa com o fornecimento de dinheiro para os empresários. Por isso, 
o destino das firmas depende da dinâmica monetária da economia, pois é a política monetária que indica o curso provável da dinâmica da taxa de juros futura.

Dado que a efetividade de uma inovação, sobretudo em termos radicais, depende da velocidade da difusão tecnológica, é possível que a incerteza quanto ao comportamento futuro da taxa de juros e da inflação interfira no estado de confiança do empresário. Isso porque a própria atratividade do esforço inovativo pode demonstrar-se inócua no longo prazo, após flutuações na taxa de juros, que modifiquem a eficiência marginal do capital. Ademais, o comportamento dos preços da economia poderá afetar a renda dos consumidores, de modo que a demanda agregada não se ajuste ao patamar esperado, frustrando a expectativa de ganhos adicionais com a adoção de uma nova tecnologia. Nesse sentido, ao se observar o fluxo do ambiente de incerteza da firma em epigrafe na Figura 2, nota-se que a dinâmica monetária também exercerá influência sobre a trajetória tecnológica. Isso porque o próprio sistema financeiro "é parte integral do sistema nacional de inovação, uma vez que os arranjos de financiamento são fundamentais para o desenvolvimento de atividades de P\&D”(Paula, 2011, p. 11). Portanto, a prevalência de uma inovação empresarial dependerá da capacidade da firma em adaptar-se às condições tecnológicas do sistema de inovação e monetárias do sistema financeiro, em constante "sobrevida" ao esforço inovativo interno, de modo que este investimento seja selecionado.

\section{Considerações finais}

Este artigo teve como objetivo analisar a relação epistemológica entre a semântica keynesiana e neo-schumpeteriana de incerteza, expectativa e esforço inovativo. Especificamente, buscou comparar a noção de esforço inovativo sob condição de incerteza a partir da epistemologia vinculada ao binômios probabilidade-peso do argumento, expectativa-estado de confiança e o trinômio busca-rotina-seleção. $\bigcirc$ artigo apresenta uma contribuição exploratória para a teoria do esforço inovativo, ao integrar duas abordagens que tratam o conhecimento como elemento norteador deste tipo de esforço. 
A articulação entre as abordagens keynesiana e evolucionária, tomando como referência a inovação, demonstra-se factível. Elementos inseridos em ambas as abordagens - incerteza, investimento e a formação de expectativas - demonstram-se relevantes para discutir os determinantes da inovação. Em Keynes, a incerteza atrelase ao processo de formação de expectativas, sendo elemento crucial para definir a tomada de decisão dos empresários quanto ao investimento. $\bigcirc$ investimento, por sua vez, depende do grau de confiança que os empresários mobilizam a partir dos conhecimentos advindos do processo lógico de decisão probabilística. Em uma economia monetária da produção, o processo decisório será direcionado pelo conhecimento das informações de mercado e pelas previsões que os empresários estabeleceram racionalmente sobre o futuro, considerando, para tanto, a eficiência marginal do capital aplicado à produção.

Os neo-schumpeterianos, contudo, atrelam o nível de investimento às expectativas de realização de lucros, que dado o caráter evolutivo e seletivo do mercado, só será possível mediante a modernização dos estoques de capital fixo, através da inovação incremental e radical. Nesse particular, as expectativas quanto aos retornos dos investimentos em inovação serão dadas em função do conhecimento que os empresários serão capazes de mobilizar para realizarem adaptações nas trajetórias tecnológicas ou desenvolverem novos paradigmas tecnológicos, com o objetivo de minimizarem custos, ampliarem demanda e se posicionarem estrategicamente perante os concorrentes. Nesse sentido, tanto para Keynes, como para os economistas neo-schumpeterianos, a tomada de decisão referente aos investimentos perpassa a formação das expectativas e as incertezas que as determinam, considerando o impacto que a mudança no estoque de capital proporcionará aos rendimentos da produção, ainda que com enfoques distintos.

Observa-se uma complementariedade na noção de expectativas keynesiana sobre as decisões de investimentos em inovação postulada pelos neoschumpeterianos, pois que a radicalização dos paradigmas tecnológicos exigirá uma gama de conhecimentos complexos, que só se viabilizará no longo prazo, após a continua experimentação das trajetórias tecnológicas. Demonstra-se, dessa forma, os conceitos de ECP e ELP importantes para explicar a forma como a inovação vincula- 
se aos investimentos intertemporais do empresário. Portanto, conclui-se que a emergência de um novo paradigma tecnológico altera a eficiência marginal do capital previamente mobilizado, visto que as inovações radicais alteram os rendimentos prospectivos do esforço inovativo.

No geral, aponta-se que o conhecimento técnico, gerencial e tecnológico, quando conjugados, formam a base epistemológica utilizada pelo empresário para contornar a incerteza e, assim, formar suas expectativas de curto e longo prazo para empreender o esforço inovativo. Nota-se pela comparação semântica e inferência ontológica empregada no artigo, quanto maior a sistematização do conhecimento, maior é o grau de confiança dos empresários para se empreender inovação, o que se reverbera na disposição para operar mudanças tecnológicas mais disruptivas. Por isso, entende-se que a própria aquisição de conhecimento, revelada por investimentos monetários em processos de aprendizados vinculados a bases internas e externas à firma são modalidades de esforço inovativo. A representação sincrônica desses aspectos alude para uma convergência analítica, entre a noção de probabilidade-peso do argumento e expectativa-estado de confiança frente ao trinômio busca-rotina-seleção, de modo que sublinha uma complementariedade filosófica.

Nesse arcabouço, chame-se a atenção para a coexistência do conhecimento latente e lógico para a formação de expectativas dos empresários, mas cujo grau de importância varia em função do alcance disruptivo do esforço inovativo, se incremental ou radical. A partir da comparação trilateral entre conhecimento tácitocodificado, indireto-direto e inovação, chega-se à conclusão de que a aproximação teórica entre a epistemologia keynesiana e neo-schumpeteriana permitem indicar o sistema financeiro como um dos mecanismos de seleção presentes na economia monetária dinâmica. Diferenciando-se de outras abordagens, propõem-se que a dinâmica monetária não apenas interfere nas decisões de investimento em esforço inovativo, mas determina a velocidade e a prevalência das inovações produzidas no mercado. Assim, as "rotinas financeiras" encontram-se inexoravelmente ligadas à própria heurística do processo inovativo dinâmico. 
Nesse particular, o esforço inovativo não é entendido como resultado espontâneo das decisões dos empresários, pois é condicionado, em grande medida, pelo grau de maturidade do sistema de inovação e do sistema financeiro nacional. Logo, a formação de expectativas relativas ao processo inovativo pauta-se em uma heurística que busca mitigar às incertezas provenientes das barreiras tecnológicas e setoriais do mercado, como às incertezas sobre a eficiência marginal do capital (esforço inovativo), dado dinâmica monetária da economia. Em termos práticos, a moeda é relevante para explicar a maneira como ocorre a seleção das inovações de mercado. Por isso, diante da incerteza que permeia o esforço inovativo, sobretudo em países em desenvolvimento, o Estado demonstra-se preponderante para atenuar as incertezas fundamentais do processo heurístico da firma. Políticas de inovação, por exemplo, poderão ser acionadas para se corrigir distorções e assimetrias tecnológicas provocadas pela dinâmica monetária, em particular, nos países em que o baixo desenvolvimento do sistema financeiro está associado a um path dependence.

Não obstante, se reconhece que a investigação realizada neste artigo representa uma inferência preliminar sobre o papel do conhecimento na conformação do esforço inovativo empresarial, bem como das características seletivas do sistema financeiro. Um esforço adicional deve ser empregado para avançar na compreensão, a partir da visão baseada em recursos, do papel do conhecimento e da dinâmica monetária enquanto elemento macroevolutivo do processo de formação de expectativas em esforço inovativo.

\section{Referências}

Aidar, G. L., \& Terra, F. H. B. (2017). A Teoria Da Firma Pós-Keynesiana: Uma Revisão Dos Elementos Relevantes. Análise Econômica, 35(67), 21-45. doi: 10.22456/2176-5456.55545

Aidar, G. L., \& Terra, F. H. B. (2019). Um modelo de firma pós-keynesiana. Brazilian Keynesian Review, 4(2), 151. doi: 10.33834/bkr.v4i2.81

Alchian, A. A. (1950). Uncertainty, evolution anda economic theory. The Journal of 
Political Economy, 58(3), 211-221. doi: 10.1086/256940

Baptista, M. A. C. (1997). A abordagem neo-schumpeteriana: desdobramentos normativos e implicações para a política industrial. Universidade Estadual de Campinas.

Becker, G. S. (1962). Irrational behavaior and economy theory. The Journal of Political Economy, 7O(1), 1-13. doi: https://doi.org/10.1086/258584

Burlamaqui, L., \& Proença, A. (2003). Inovação, Recursos e Comprometimento: Em Direção a uma Teoria Estratégica da Firma. Revista Brasileira de Inovação, 2(1), 79. doi: 10.20396/rbi.v2i1.8648869

Cardim de Carvalho, F. J. (2015). Keynes on expectations, uncertainty and defensive behavior. Brazilian Keynesian Review, 1(1), 44-54. doi: 10.33834/bkr.v1i1.15

Carvalho, F. J. (1997). Financial innovation and the post Keynesian approach to the "process of capital formation." Journal of Post Keynesian Economics, 19(3), 461487. doi: 10.1080/01603477.1997.11490122

Christensen, J. L. (1992). The role of finance in national system of innovation. In National System of Innovation: Towards a Theory of Innovation and Interactive Learning (pp. 146-168). Printer Pub. doi: 10.7135/UPO9781843318903.009

Cohen, W. M. ., \& Levinthal, D. A. . (1989). Innovation and Learning : the two faces of R \& D. The Economic Journal, 99(397), 569-596. doi: 10.2307/2233763

Crocco, M. (1999). The neo-schumpeterian approach to innovation and Keynes's probability: initial explorations. Brazilian Journal of Political Economy, 19(4), $15-34$.

Crocco, M. (2003). A abordagem evolucionária-institucional de progresso técnico e o processo de formação de expectativas keynesiano. In Macroeconomia do emprego e da renda: Keynes e o keynesianismo (pp. 499-534).

Crocco, M. A. (2008). Technical Change and Formation of Expectations. Metroeconomica, 59(2), 276-304. doi: 10.1111/j.1467-999X.2007.00306.x

Dabic, M., Cvijanovic, V., \& Loureiro-Gonzáles, M. (2011). Keynesian, post- 
keynesian versus Schumpeterian, neo-schumpeterian. Management Decision, 49(2), 195-207. doi: https://doi.org/10.1108/00251741111109115

Dequech, D. (1999a). Expectations and confidence under uncertainty. Journal of Post Keynesian Economics, 21(3), 415-430. doi: 10.1080/01603477.1999.11490205

Dequech, D. (1999b). Uncertainty, conventions and shortterm expectation. Brazilian Journal of Political Economy, 19(3), 67-81.

Dillard, D. (1976). A teoria econômica de John Maynard Keynes. Pioneira.

Dosi, G, Tyson, L., \& Zysman, J. (1989). Trade, technologies and Development: A Framework for Discussing Japan. In Politics and Productivity: How Japan's Development Strategy Works (1st ed., Vol. 1, pp. 55-63). Harper Business.

Dosi, Giovanni. (1988). Sources, Procedures, and Microeconomic Effects of Innovation. Journal of Economic Literature, 26(3), 1120-1171.

Dosi, Giovanni, Fagiolo, G., \& Roventini, A. (2010). Schumpeter meeting Keynes: A policy-friendly model of endogenous growth and business cycles. Journal of Economic Dynamics and Control, 34(9), 1748-1767. doi: 10.1016/j.jedc.2010.06.018

Dosi, Giovanni, \& Orsenigo, L. (1988). Coordination and transformation: an overview of structures, behaviours and change in evolutionary environments. In Pinter Publishers (Ed.), Technical Change and Economic Theory (pp. 13-37).

Eichner, A. S. (1985). Uma teoria da determinação do "mark-up" sob condições de oligopólio. Ensaios FEE, 6(2), 3-22.

Enke, S. (1951). On Maximizing Profits: A Distinction Between Chamberlin and Robinson. The American Economic Review, 41(4), 566-578.

Feijó, C. A. (1993a). A firma em um ambiente inflacionário: uma visão póskeynesiana. Análise Econômica, 11(1), 122-135. doi: 10.22456/21765456.10456

Feijó, C. A. (1993b). Decisões empresariais numa economia monetária de produção: notas para uma teoria pós-keynesiana da firma. Revista de Economia Política, 
13(1), 82-100.

Feijó, C. A., \& Valente, E. (2004). A firma na teoria econômica e como unidade de investigação estatística: evolução nas conceituações. Revista de Economia Contemporânea, 8(2).

Ferrari Filho, F. e, \& Conceição, O. A. C. (2001). A noção de incerteza nos póskeynesianos e institucionalistas: uma conciliação possível? Nova Economial Belo Horizonte, 11(1), 99-122.

Ferrari Filho, F., \& Terra, F. H. B. (2016). Reflexões sobre o método em Keynes. Revista de Economia Política, 36(1), 70-90. doi: 10.1590/010131572016v36n01a05

Freeman, C. (1974). The economics of industrial innovation. Peguin Modern Economic Texts.

Freeman, C., \& Soete, L. (1997). The economics of industrial innovation (1st ed.). Penguin Books.

Friedman, M. (1953). The Methodology of positive Economics. In Essays in Positive Economics (pp. 3-43). University of Chicago Press.

Hodgson, G. M. (1998). Evolutionary and competence- Based theories of the firm. Journal of Economic Studies, 25(1).

Keynes, J. M. (1921). A Treaties on Probability. Macmillan.

Keynes, J. M. K. (1936 [1996]). A teoria geral do emprego, do juro e da moeda (E. N. Cultural (ed.); 7th ed.). Editora Nova Cultural.

Kupfer, D. (1992). Padrões de concorrência e competitividade. Research Gate, 1-17.

Malerba, F. (1992). Learning by Firms and Incremental Technical Change. The Economic Journal, 102(413), 845-859. doi: 10.2307/2234581

Malerba, F. (2005). Sectoral systems of innovation: A framework for linking innovation to the knowledge base, structure and dynamics of sectors. Economics of Innovation and New Technology, 14(1-2), 63-82. doi: 10.1080/1043859042000228688 
Malerba, F., \& Orsenigo, L. (1997). Technological Regimes and Sectoral Patterns of Innovative Activities. Industrial and Corporate Change, 6(1), 83-118. doi: 10.1093/icc/6.1.83

Minsky, H. (1986). Stabilizing na ustable economy. Yale University Press.

Moura da Silva, A. (1996). Prefácio. In A teoria geral do emprego, do juro e da moeda. (pp. 4-22). Editora Nova Cultural.

Nelson, R. (2006). Por que as firmas diferem e qual é a importância disso? As Fontes do Crescimento Econômico. Unicamp.

Nelson, R., \& Winter, S. (1977). In search of useful theory of innovation. Research Policy, 6(1). doi: 10.1007/978-3-0348-5867-0_14.

Nelson, R., \& Winter, S. (2005). Uma teoria evolucionária da mudança econômica (1st ed.). Unicamp.

O’Sullivan, M. (2005). Finance and innovation. In J. Fagerberg, .D.C. Momery, \& R. R. Nelson (Eds.), The Oxford Handbook of Innovation. Oxford University Press. doi: 10.1093/oxfordhb/9780199286805.003.0009.

Paula, L. F. De. (2011). Sistema financeiro e o financiamento da inovação: Uma abordagem keynesiana - Schumpeteriana. Anais do $39^{\circ}$ Encontro Nacional de Economia, 1-16. Disponível em: https://www.anpec.org.br/encontro/2011/inscricao/arquivos/0006135c1601d8e2b4bd8b96e15baf72c5d.pdf. Acesso em 14 mai de 2019.

Pavitt, K. (1984). Sectoral patterns of technical change: Towards a taxonomy and a theory. Research Policy, 13(6), 343-373. doi: 10.1016/0048-7333(84)90018-0

Perez, C. (2020). Technological revolutions and financial capital. Edward Elgar Publishing.

Possas, M. L. (1988). Em direção a um paradigma microdinâmico: a abordagem neoschumpeteriana. In J. Amadeo, E (Ed.), Ensaios sobre Economia Política Moderna: teoria e história do pensamento econômico (pp. 157-178). Marco Zero. 
Possas, M. L. (2008). Economia evolucionária neo-schumpeteriana: elementos para uma integração micro-macrodinâmica. Estudos Avançados, 22(63), 281-305. doi: 10.1590/S0103-40142008000200021

Romero, J. P. (2014). Mr. Keynes and the neo-Schumpeterians: Contributions to the analysis of the determinants of innovation from a post-Keynesian perspective. EconomiA, 15(2), 189-205. doi: 10.1016/j.econ.2014.06.001

Schumpeter, J. A. (1911 [1997]). Teoria do desenvolvimento econômico: uma investigação sobre lucros, capital, crédito, juro e o ciclo econômico (3rd ed.). Editora Nova Cultural.

Schumpeter, J. A. (1949 [2016]). Capitalismo, socialismo e democracia. In Fundo de Cultura. Fundo de Cultura.

Simon, H. A. (1978). Rationality as Process and as Product of Thought Author. American Economic Review, 68(2), 1-16.

Simon, H. A. (1987). Bounded rationality. In J. EATWELL, M. MILGATE, \& P. NEWMAN (Eds.), The New Palgrave - Utility and Probability. Macmillan Publishing. doi: 10.1007/978-1-349-20568-4_5

Terra, F. H. B., \& Goudard, G. C. (2015). Incerteza, tomada de decisão, hábito e instituição: uma possível articulação entre keynesianos e neoinstitucionalistas. Encontro Nacional de Economia Política, 1-19.

Vercelli, A. (1991). Methodological foundations of macroeconomics: Keynes and Lucas (1 ed.). Cambridge University Press.

Vercelli, A. (2010). Weight of argument and economic decisions. Siena, Department Of Economic Policy, Finance And Development at University Of Siena Working Paper, n.6-2010, 25p.

Winter, S. G. (1984). Schumpeterian competition in alternative technological regimes. Journal of Economic Behavior and Organization, 5(3-4), 287-320. doi: 10.1016/0167-2681(84)90004-0 